\title{
PIBID/ESPANHOL: A LEITURA LITERÁRIA, A CRIATIVIDADE E O ENSINO DE ELEC
}

\author{
Claudia Paulino de Lanis Patricio ${ }^{1}$
}

Tatiana Marta de Lima Marianelli ${ }^{2}$

\begin{abstract}
Resumo: O presente trabalho visa a apresentar e discutir os resultados de uma das práticas realizadas no ensino da leitura literária nas aulas de língua estrangeira na educação infantil desenvolvidas no Pibid Espanhol/2018. Para isso, decidiu-se expor de forma crítica uma das ações desenvolvidas com alunos do grupo 4 da escola CEI Criarte/Ufes por uma bolsista integrante do Pibid. Entendemos que as literaturas são fundamentais para a aprendizagem de línguas uma vez que refletem os modos de vida dos povos que as produzem, oferecem repertório para a compreensão do mundo que nos rodeia e também contribuem para a formação emotiva e cidadã do indivíduo. Desse modo, o nosso objetivo é promover uma reflexão sobre o ensino lúdico e contextualizado das literaturas estrangeiras nas aulas de línguas na educação infantil. Destacamos, assim, o ensino mais significativo, a familiarização com a cultura do outro e da sua própria, bem como o desenvolvimento da criatividade e da imaginação como resultados observados. Como referencial teórico, utilizamos Cameron (2001), Almeida Filho (1993) e Schütz (2008) sobre o ensino de língua estrangeira a crianças; Clímaco e Ortega (2018) sobre o ensino de literaturas hispânicas; Colomer (2017) sobre a leitura literária e Borges e Mozzer (2008) sobre a criatividade.
\end{abstract}

Palavras-chave: Pibid. Literatura. Espanhol. Criatividade.

Abstract This present work aims to show and discuss the results of one of the practices carried out in the teaching of literary reading in foreign language classes at a kindergarten developed by Pibid Spanish/2018. In order to accomplish that, it was decided to expose in a critical way one of the actions developed by the students of group 4 at CEI Criarte kindergarten/UFES by a Pibid scholarship holder. We understand that different literatures are paramount for language learning, once they reflect the diverse ways of living from the people that produce them. They also offer a great repertoire for world understanding. In addition to this, they contribute to the emotional and citizen formation of each individual. This way, our objective is to promote the mediation about playful and contextualized teaching of the foreign literatures in a language kindergarten class. Hence, we highlight a more meaningful teaching, a familiarization with lots of different cultures and our own, as well as with the creativity development and imagination as observed results. As theoretical referential, we use Cameron (2001), Almeida Filho (1993) and Schütz (2008) about foreign language teaching for children; Ortega and Clímaco (2018) about spanish literatures teaching; Colomer (2017) about literature reading and Borges and Mozzer (2008) about creativity.

keywords: Pibid. Literature. Spanish. Creativity.

\section{Introdução}

\footnotetext{
${ }^{1}$ Departamento de Línguas e Letras (DLL/CCHN), UFES, Vitória, ES, Brasil, claudiaplanis@ gmail.com

${ }^{2}$ UFES, Vitória, ES, Brasil, mlima.tatiana@gmail.com
} 
"a atividade criativa faz o seguinte: está atenta para o futuro, criando-o e mudando a visão do presente" (Vygotsky, 2009, p. 85)

Há diversos estudos sobre o desenvolvimento da criatividade na infância, entre eles os de Tommasi (2010) e Silva (1999), por exemplo. No entanto, definir esse termo não consiste em uma tarefa simples, pois o seu conceito possui uma gama de significados. A criatividade se manifesta em todas as áreas da atividade humana, por isso seu conceito se torna complexo, visto que as ciências envolvidas proporcionam concepções distintas. De maneira geral, a criatividade está associada à capacidade de gerar algo novo e de valor social.

$\mathrm{Na}$ antiguidade, a filosofia considerava a criatividade não só parte da natureza humana, como um dom divino, mas também a relacionava à loucura, ou seja, as demonstrações criativas eram julgadas como um ato impensado. Segundo Albert e Runco (1999), a criatividade deixou de ser vista como originária do divino a partir do renascimento e passou a ser considerada uma habilidade dos "grandes homens". Paty (2001, p.7) afirma que, em fins do século XIX e início do XX, Helmholtz refletiu sobre seu próprio trabalho criativo e identificou o período de investigação, de descanso e a ocasião em que a solução surgia inesperadamente. Em 1902, Poincaré trata das distintas etapas da criação. No entanto, o filósofo, lógico e matemático britânico Alfred North Whitehead foi considerado o criador do termo "criatividade". Embora essa temática tenha recebido, ao longo da história da humanidade, contribuições de diversos estudiosos, até a presente data não foi possível chegar a uma conceituação convergente.

Para Cunha (2000), Piaget (2001) e Tommasi (2010), por exemplo, a criatividade pode ser desenvolvida nos seres humanos; já Sans (2001), que parte de uma visão determinista sobre tema, afirma que ela consiste em uma habilidade inata, ligada a fatores hereditários. Acredita-se, então, que o humano tenha início na infância. Sendo assim, é durante essa fase que esse potencial pode ou não ser ativado, pois seu desenvolvimento é devido aos estímulos e elogios recebidos pela criança. Para os estudiosos da criatividade, as crianças estimuladas, elogiadas tendem a ser adultos ousados, predispostos a atuar de maneira inovadora.

A exposição do cérebro a uma grande e diversa quantidade de conhecimentos e informações favorece a ocorrência de associações de ideias de uma forma mais fluida e criativa. Desse modo, a união entre o ensino, a leitura literária e a proposta de atividades artísticas em 
aulas de língua espanhola para crianças poderá ser uma tática eficiente para o estímulo à criatividade dos discentes.

No mundo globalizado, a evolução tecnológica dos meios de comunicação rompeu as barreiras físicas de maneira que o domínio de uma língua estrangeira adquiriu importância no âmbito profissional. Assim, o aprendizado de outro idioma tornou-se importante para possibilitar o contato com diferentes culturas, ampliar o conhecimento de mundo e enriquecer a bagagem cultural do indivíduo. Neste sentido, o ensino-aprendizagem de língua estrangeira, ainda na fase da infância, possibilita e amplia o espaço de discussão sobre o aspecto cultural.

Os estudos de Rocha (2007), Boéssio (2010), Tonelli (2005), Rinaldi (2006) e Pereira (2016) apresentam questões relacionadas ao ensino de língua estrangeira para crianças, tratam da ausência de diretrizes curriculares oficiais para a etapa infantil até o quarto ano do ensino fundamental, da formação (ou falta dela) teórico-prática do docente, da antecipação da aprendizagem para crianças menores, das possíveis abordagens metodológicas de ensino, da escassez de material didático e da atuação do professor de língua estrangeira para crianças (doravante LEC). Visto que tais estudos se referem, em sua maioria, aos primeiros anos do ensino fundamental e ao idioma inglês, na fase pré-escolar, no que tange ao idioma espanhol na primeira infância, torna-se então um campo a ser explorado.

\section{Subprojeto de Iniciação à Docência: Leitura literária em espanhol}

Nesta seção, apresentaremos um dos resultados das ações realizadas no Centro de Educação Infantil (doravante CEI) Criarte durante a atuação do subprojeto Pibid Espanhol LEITURA LITERÁRIA realizado de agosto de 2018 a dezembro de 2019. Apesar do subprojeto ter abarcado três escolas públicas no estado do Espírito Santo, sendo duas delas escolas de ensino médio e uma de ensino infantil, selecionamos a de educação infantil para discorrer neste trabalho. Nossa metodologia consistiu em encontros semanais entre professor supervisor e licenciandos e planejamentos conjuntos entre pibidianos, professor regente, supervisor e coordenador do Pibid; coube ao supervisor do subprojeto proporcionar aos pibidianos diversas experiências sobre o papel do professor: uso de diferentes atividades em uma sala de aula; postura do profissional de língua estrangeira; planejamentos de aula a fim de propiciar a autonomia do aluno em formação a partir do desenvolvimento de atividades com grau de 
complexidade crescente, ou seja, o Pibid fomentou o conhecimento e a práxis do licenciando no contexto educacional.

A formação para a docência em línguas e literaturas exige dois períodos de estágio obrigatório. No entanto, como o Estágio Supervisionado é ofertado somente nos períodos finais da graduação, a vivência no ambiente em que o discente atuará consiste em um desafio para o aluno. Por isso, o Pibid colabora muito com a formação do graduando em Letras, pois permite, no caso do edital de 2018/2019, a prática do estudante de Letras durante 18 meses na escola básica.

Entendemos que, por propiciar a experiência com a leitura como prática emancipatória e a expressão oral como modo de inserção nas comunidades discursivas da contemporaneidade, o acesso às línguas contribui para uma formação humanista, ou seja, para a vida e não apenas para o mercado de trabalho, embora também o inclua no horizonte de seus desdobramentos positivos.

O CEI Criarte, da Universidade Federal do Espírito Santo (Ufes), recebeu os graduandos de Letras Espanhol para atuarem nas atividades de aprendizagem de língua espanhola. A formação docente dos estagiários é contínua e pautada em reflexões acerca do processo ensino-aprendizagem de línguas estrangeiras. Almejou-se, por meio desse projeto, que os bolsistas tivessem possibilidades de desenvolvimento acadêmico e profissional e que as crianças do CEI Criarte tivessem a oportunidade da leitura literária em espanhol e, desse modo, desenvolvessem-se linguístico, cultural e literariamente.

Os objetivos desse subprojeto são definitivamente relevantes e condizentes com a função da Universidade, quais sejam, propiciar complementação de formação aos alunos dos cursos de Letras da UFES e estender à comunidade a aprendizagem de línguas, em especial com relação aos cursos de licenciatura em Letras, a partir de um programa de formação continuada e por intermédio de reflexões sobre o processo ensino-aprendizagem em sua relação com os fatores sociais, afetivos e cognitivos dos atores envolvidos. Os bolsistas refletiram acerca de sua atuação e desempenho como um processo dinâmico e complexo, sujeito a mudanças e adaptações. As ações do programa de formação se fortaleceram mediante atividades extracurriculares e cursos especiais ministrados por professores, escritores e artistas convidados, que funcionaram como um canal permanente na troca de ideias, apoiando os bolsistas na elaboração dos cursos, na preparação de materiais, na avaliação da aprendizagem e na discussão das situações cotidianas de sala de aula, o que auxiliou na superação do ponto de vista tecnicista no campo das línguas. 
Além do objetivo geral supracitado, os objetivos específicos do subprojeto consistiram em: proporcionar o ensino de línguas estrangeiras e suas culturas a crianças; colaborar para a formação linguística, profissional e acadêmica dos alunos do curso de Letras Português/Espanhol; fortalecer a concepção de uma educação linguística humanista, comprometida com a diversidade linguística e cultural; propiciar a ampliação do horizonte linguístico e cultural da comunidade, constituindo valiosa ferramenta para a construção de uma sociedade mais democrática e justa. A aprendizagem de línguas é considerada essencial à participação ativa em um mundo no qual constantemente se afunilam o distanciamento e onde a aquisição de novas informações é essencial para o conhecimento científico, filosófico, para a expressão artística e para o desenvolvimento profissional e econômico.

Assim, almejamos uma aprendizagem de línguas que aspire o aprimoramento cognitivo, afetivo, acadêmico e cultural; uma visão de língua que propicie aos alunos a reflexão crítica, evitando tanto o aculturamento submisso quanto o reducionismo pragmático. Em síntese, buscamos aguçar nos educandos o desejo e o prazer pela aprendizagem de línguas, ademais das necessidades imediatas amiúde referenciadas ao mercado, e oferecer aos discentes um estímulo constante para o seu desenvolvimento intelectual, pessoal e social.

Entendemos que esse projeto visou a contribuir para a formação educacional e profissional dos bolsistas e das crianças que frequentaram o CEI Criarte, já que ponderamos a relevância do ensino de línguas e os benefícios de ensinar e aprender uma língua para os envolvidos nesse processo.

Há questionamentos acerca da aprendizagem precoce de uma língua estrangeira (doravante LE), no entanto concordamos com Lightbown e Spada (2006), que atestam os benefícios de iniciar o ensino de LEC, já que a aproximação à língua, desde a primeira infância, pode favorecer a aquisição de algumas estruturas e sons. Outrossim, corroboramos a afirmação de Rocha (2009) pautada nos estudos de Cameron (2001) a qual demonstra o grande potencial das crianças para aprendizagem, pois elas são participativas e motivadas. Todavia, começar a estudar LE nos anos iniciais da infância não avaliza um resultado vitorioso; assim como nos advertiu Rocha (2009, p. 250), "resultados positivos no ensino-aprendizagem de línguas na infância dependem, também, da preocupação em buscar compreender e respeitar a individualidade da criança, seus diferentes valores, visões e experiências de vida".

Destarte, buscamos avaliar as atividades que seriam utilizadas em sala de aula, levando em consideração experiências de ensino-aprendizagem que fossem significativas para as crianças e apropriadas ao perfil de desenvolvimento físico-motor e cognitivo desse público, 
refutando então as propostas simplificadas de ensino-aprendizagem de LE pautadas em abordagens estruturais e gramaticais ou mesmo as tradicionais listas de vocabulário que são características em algumas atuações corriqueiras para essa faixa etária. Procedemos, assim, em conformidade com a perspectiva de Rocha (2007), para a qual o ensino de LEC deve, além de promover o desenvolvimento linguístico, contribuir para o crescimento intelectual, físico, emocional e sociocultural da criança; perspectiva essa que corrobora os estudos de Moon (2005) e Cameron (2001).

Desse modo, coincidimos com Rocha (2007, p. 280) em relação ao que é relevante para o ensino-aprendizagem de LEC: "a interculturalidade revela-se como o elemento propulsor do crescimento lingüístico, intelectual, físico, emocional e sócio-cultural do aprendiz-criança". Para tratar da cultura e da interculturalidade nas aulas de espanhol com as crianças do grupo 4, propusemos a leitura de textos literários produzidos em língua espanhola, pois a literatura, com sua imensa capacidade de encantar e modificar vidas, não poderia ficar de fora do processo ensino-aprendizagem de língua estrangeira.

O subprojeto iniciação à docência "Leitura Literária" pretendeu assim unir literatura de LE e ensino de LEC, bem como estreitar os vínculos da universidade com a escola para possibilitar aos graduandos a vivência da profissão ainda no período de formação inicial. Em conformidade com esse objetivo principal, possibilitamos ao aluno imergir no mundo mágico da leitura, praticar a oralidade e, consequentemente, conhecer outras culturas de língua estrangeira. Este último objetivo específico deu oportunidade tanto ao aluno bolsista do Pibid, quanto ao aluno do ensino infantil, ao ler obras literárias de determinada cultura, de colocar-se no lugar do outro e entender, por intermédio da magia literária, a forma como pensa o outro. Como asseverou Côrrea, "sabemos que ler não é apenas decodificar, é compreender e, mais ainda, é indagar, deduzir, inferir, associar, intuir, prever, concluir, discordar, concordar, acrescentar, selecionar, entre outras formas de interpretar e fruir o texto" (CORRÊA, 2003, p.53).

O subprojeto objetivou a inserção do graduando no cotidiano de escola da rede pública de educação e a qualidade de práticas acadêmicas voltadas à formação inicial de professores. O programa Pibid proporcionou a participação de discentes de licenciatura em experiências docentes inovadoras e interdisciplinares que buscaram a superação de problemas identificados no processo ensino-aprendizagem.

Almejamos estimular o gosto pela leitura a partir de textos literários hispânicos. Nesse sentido, por meio de uma metodologia lúdica e crítica, propiciamos aos licenciandos a produção 
de materiais didáticos, a partir de textos literários, para desenvolver o prazer da leitura em língua espanhola, bem como o fomento à leitura literária entre os estudantes do ensino infantil, assim como também a construção de práticas que correlacionam os conhecimentos linguísticos, textuais e discursivos (sócio-histórico-ideológicos), tendo em vista a ampliação e o aprofundamento das habilidades de leitura com viés crítico.

Para a consolidação do projeto, realizamos encontros periódicos a fim de preparar os bolsistas de iniciação à docência, graduandos em Letras Português-Espanhol e supervisores. Nesse momento, fizemos leituras de textos teóricos que versaram sobre o ensino da leitura de textos literários e o ensino da expressão oral em língua espanhola. Os bolsistas de iniciação à docência, sob orientação dos supervisores e dos coordenadores, elaboraram planos de aula e materiais didáticos que foram postos em prática no CEI Criarte para o desenvolvimento da leitura de textos, com o intuito de realizar atividades lúdicas e criativas, como rodas de leitura, leituras compartilhadas, entre outras expressões artístico-literárias. Tais práticas passaram por contínuos planejamentos e avaliações, de maneira a possibilitar a reflexão acerca dos aspectos positivos e negativos das ações realizadas.

\section{Práxis: Leitura literária em espanhol e ensino LEC}

Para Teresa Colomer (2017, p.2), professora da Universidade Autônoma de Barcelona e também escritora, os textos literários consistem no melhor instrumento que possuímos para adquirir muitas competências. Segundo a pesquisadora,

La literatura resulta el mejor instrumento que poseemos para adquirir muchas competencias. Para dominar el lenguaje y la lectura, para advertir cómo el lenguaje busca efectos en el receptor o cómo nos endosa implícitos que nos permiten valorar el lenguaje publicitario, político, financiero, etc.

Ainda segundo Colomer, o imaginário literário nos educa sentimentalmente. Ao contrário do que vem acontecendo com o ensino de literatura em muitas escolas, não deveríamos centrar a educação em uma perspectiva utilitarista, que não fomenta uma formação cidadã desejável, para não tornar a educação literária um luxo prescindível. Nessa perspectiva, Antônio Cândido (2011, p. 176) destacou a imprescindibilidade da literatura para o homem ao 
afirmar que "Assim como todos sonham todas as noites, ninguém é capaz de passar as vinte e quatro horas do dia sem alguns momentos de entrega ao universo fabulado".

Segundo Escalante e Caldera (2008), a literatura infantil não somente é o primeiro contato da infância com as criações literárias, mas também constitui um recurso excelente para que os alunos desenvolvam sua personalidade, criatividade e imaginação. A literatura, ainda de acordo com Escalante e Caldera (2008), também tem um impacto no desenvolvimento pessoal e social da criança, posto que contribui para a criação de laços afetivos entre o adulto que lê e o grupo de alunos.

Portanto, pensar as práticas pedagógicas e a seleção de textos para o público infantil ganha ainda mais importância e requer prudência por parte do professor uma vez que entram em cena questões como faixa etária, variedade de atividades, autenticidade do texto, temas e elementos estéticos, como ilustrações, dimensões do livro, forma e tamanho de letras etc. Assim, como afirmou Colomer (2017), as crianças devem ter uma literatura que se adapte a sua capacidade de leitura e a sua experiência de vida. Embora haja algumas obras que não tenham sido escritas para o público infantil e que, ao contrário, sejam accessíveis e atrativas, o professor deve estar atento para as necessidades, interesses, emoções e intelecto das crianças a fim de não ocorrer nenhuma surpresa indesejada durante a sua aula que obstaculize atingir os objetivos estipulados.

De acordo com Boéssio (2010) e Rinaldi (2006), o idioma estrangeiro na educação infantil visa à sensibilização das crianças a outras línguas e culturas. As autoras acreditam que, deste modo, minimizam-se ou evitam-se futuros preconceitos e atitudes negativas do indivíduo no processo ensino-aprendizado de LE. Rocha (2007) propõe a abordagem didática por temas orientados por tarefas e entende que "o trabalho a partir de projetos parece, também, oferecer a possibilidade da concretização de um ensino que prime pela construção de sentidos e que seja significativo para o aluno". Esta autora destaca também que os gêneros discursivos fazem parte do universo infantil, como a música, a dramatização, os jogos/brincadeiras e as histórias. As pesquisadoras supracitadas destacam o uso da ludicidade como enfoque metodológico a ser empregado pelo professor em suas práticas didáticas, pois propicia uma aprendizagem de LEC significativa e contextualizada.

A ludicidade no âmbito escolar tem por objetivo o ensino de determinado conteúdo de forma prazerosa e divertida para proporcionar a formação de um ambiente acolhedor e motivador. Para Tonelli (2005, p. 106), as atividades, como dramatização, desenho, recortes, brincadeiras, criação de textos orais ou escritos e construção de personagens estimulam a 
criatividade e a imaginação dos pequenos; portanto, contribuem para o ensino de espanhol como língua estrangeira para crianças (ELEC). A pesquisadora Colomer (2017) também expõe alguns conselhos para instigar a leitura literária na sala de aula: criar um entorno recheado de obras, tanto fisicamente como em leituras em voz alta, por parte do professor, de maneira frequente; oportunizar tempo de leitura autônoma na sala de aula; conceder tempo de discussão sobre livros em sala de aula; conhecer muito bem os livros que vamos recomendar às crianças; associar a leitura a atividades criativas, muito diversificadas e com sentido; levar a cabo atividades que reforcem a autoimagem como leitores, como, por exemplo, jogos de evocação dos livros lidos; frequentar bibliotecas; assistir a peças teatrais etc.

A partir de agora, relataremos uma de nossas práticas realizadas no CEI Criarte com uma turma denominada Grupo 4 matutino, constituída por 20 alunos de 4 a 5 anos. Nossos encontros com esse grupo eram semanais e duravam em torno de uma hora. Uma das rotinas da escola é, no início de cada semestre, observar as demandas das crianças por, aproximadamente, uma semana para, assim, decidir o tema do projeto escolar a ser desenvolvido. $\mathrm{O}$ edital Pibid $\mathrm{n}^{\circ}$ 003/2018 deu início a suas atividades em agosto de 2018 e, por isso, as crianças já tinham começado o projeto que se intitulava "Os seres fantásticos do pátio". Esse tema foi escolhido devido ao intenso interesse das crianças pelos animais do pátio da escola, um dos ambientes preferidos dos alunos em seu cotidiano escolar. Nesse espaço, plantas, frutas, insetos e aves foram os objetos de estudo. Pareceu-nos melhor escolher uma obra literária que se valesse do conhecimento prévio dos alunos. Visto que as aves já constituíam um tema familiar e contextualizado na vivência das crianças, o livro Pájaro Amarillo de 2015, da autora espanhola Olga de Dios, foi a obra escolhida para desenvolver o subprojeto Pibid Espanhol.

O enredo de Pájaro Amarillo destaca a dificuldade de um pássaro em voar porque tem as asas pequenas. Ele é muito inteligente e gosta de inventar objetos e compartilhá-los com os amigos. No entanto, ele deseja voar como as outras aves e viajar para conhecer outros lugares. Por isso, ele inventa uma mochila voadora e inicia sua aventura. Ao longo da trajetória da viagem, conhece outras aves que, assim como ele, não podiam voar. O personagem principal de Pájaro Amarillo ajuda esses novos amigos a voarem também. Ao final de sua jornada, chega a um lugar fantástico e decide residir lá.

A metodologia adotada por nós consistiu em apresentar a obra Pájaro Amarillo ao longo do semestre, criando, assim, uma rotina quase cíclica de revisão e ampliação do conteúdo de maneira gradual e constante. Repassávamos de outra forma o que já tinha sido estudado em aulas anteriores e acrescentávamos informações novas dentro do que havia sido planejado. Os 
temas extraídos da leitura literária foram abordados de forma lúdica, fazendo uso de atividades manuais, jogos, brincadeiras e música com o objetivo de promover um clima divertido, prazeroso e motivador para a aprendizagem do idioma espanhol e da leitura literária.

$\mathrm{Na}$ fase do planejamento, ao analisar a narrativa, optamos por três eixos temáticos a partir dos quais pautamos as atividades de nossas aulas: aves, invenções e viagens.

Foi perceptível que a leitura literária despertou a curiosidade das crianças, estimulou a criatividade, a imaginação e o trabalho em equipe. Apresentamos às crianças as aves por suas características físicas, habitat e capacidade de voo.

Na segunda aula, após a leitura das páginas 4 e 5 de Pájaro Amarillo, objetivamos que as crianças percebessem as semelhanças e diferenças entre os diversos tipos de ovos: de codorna, de pato, branco e caipira. Para isso, levamos os ovos para a sala de aula. Após observar e manusear diferentes tipos de ovos, elas puderam fazer comparações e formular hipóteses bem criativas sobre a que tipo de aves estes ovos estavam relacionados. Ficaram encantadas por tocar e ter uma experiência sensorial envolvendo a percepção de tamanho, peso e cor dos ovos. Percebeu-se o quanto é importante para a criança a experienciação, a vivência direta com o objeto de estudo.

Figura 1 - Conhecendo os tipos de ovos

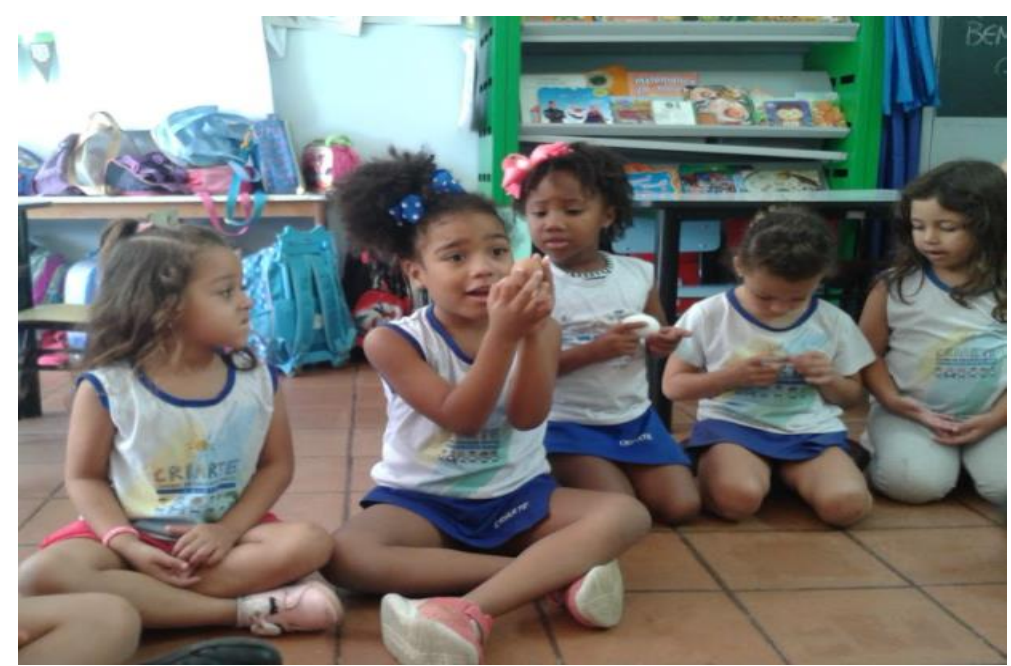

Fonte: Acervo das autoras ${ }^{3}$

\footnotetext{
${ }^{3}$ As famílias das crianças e a escola Criarte concederam autorização para a utilização das fotos apresentadas nesse artigo.
} 
PERcursos Linguísticos • Vitória (ES) •v. 11 •n. 27 • 2021 • ISSN: 2236-2592 •

Dossiê: Pibid e RP na formação de professores em Letras •

Em seguida, criamos um ninho para colocar todos os ovos. De uma folha de papel, as crianças do grupo 4 fabricaram ovos para povoar um ninho que foi colocado em uma árvore.

Figura 2 - Criando ovos de papel

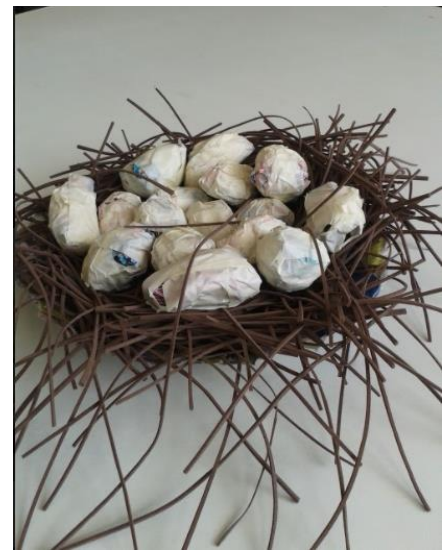

Fonte: Acervo das autoras
Figura 3 - Ninho de ovos de papel

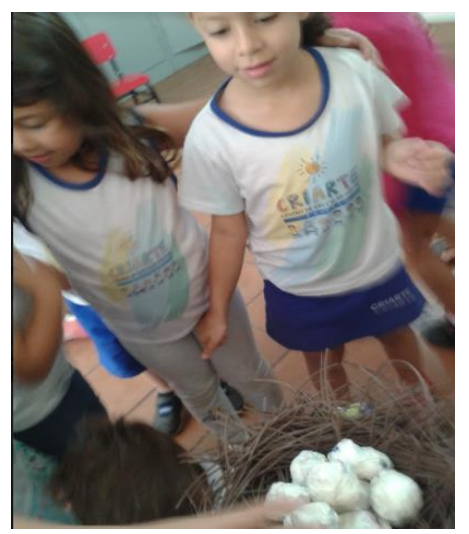

Fonte: Acervo das autoras

Os alunos dançaram o baile dos passarinhos munidos de uma máscara de pássaro, que, ao colocarem, transformaram-se em passarinhos, imitaram piados, balançaram os braços, que se transformaram em asas e voaram alegremente pela sala como se estivessem explorando o céu.

Figura 4 - Baile dos passarinhos

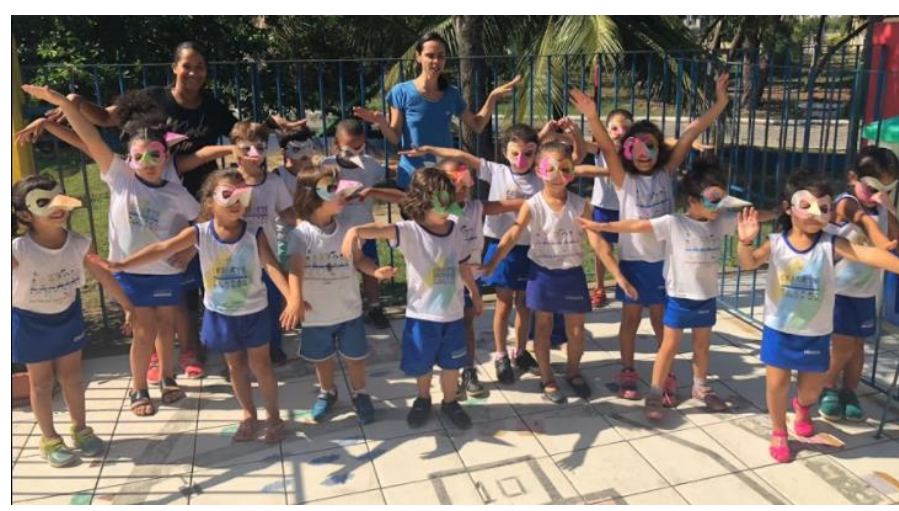

Fonte: Acervo das autoras

Em outubro de 2018, uma das atividades desenvolvidas a partir da leitura da obra de Olga de Dios foi a recriação do personagem principal por meio de carimbo de mãos. 
Figura 5 - Carimbo de mãos

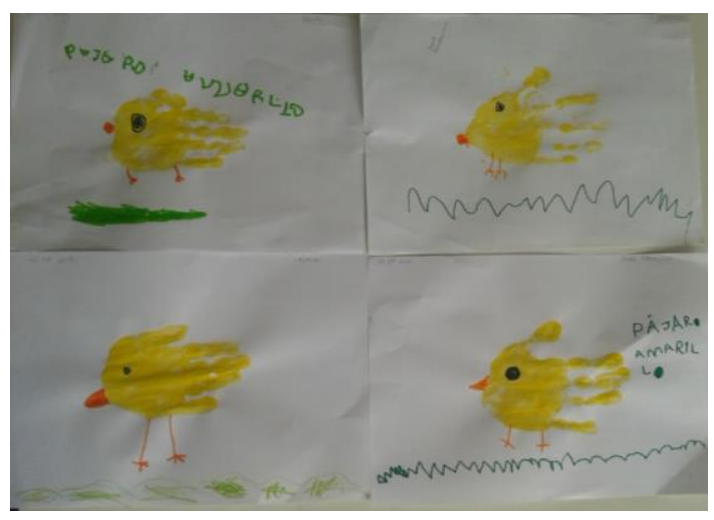

Fonte: Acervo das autoras
Figura 6 - Carimbo de mãos

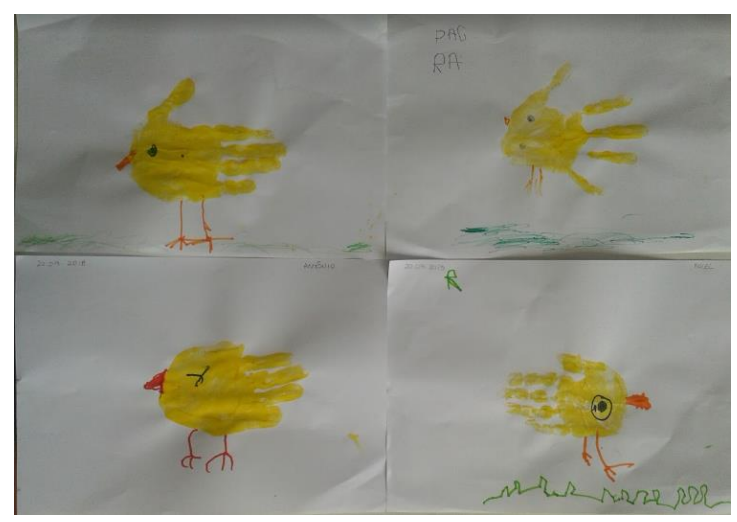

Fonte: Acervo das autoras

Na obra Pájaro Amarillo, após mostrar os tipos de ovos, as características de alguns pássaros, a capacidade do personagem principal de consertar alguns aparelhos, Olga de Dios apresenta as invenções criadas por esse personagem. Apresentamos então às crianças alguns inventos criados pelos espanhóis, como o pirulito, o submarino, o teleférico e o esfregão para relacionar o tema da obra literária à cultura espanhola. Assim, mostramos as imagens de tais inventos e perguntamos quem conhecia aquelas invenções. Com base nas repostas, reforçamos a ideia de compartilhar ao afirmar que só conhecemos esses inventos porque os seus inventores compartilharam conosco suas ideias.

A partir da apresentação dos inventos espanhóis, em especial do pirulito, propusemos uma atividade culinária a qual consistia em preparar um pirulito de gelatina. Essa proposta gerou surpresa e euforia nas crianças. Consequentemente, a cada fase da receita, os alunos se surpreendiam e tentavam entender como o líquido se transformava em sólido e adquiria a forma esférica. "Mágica!”, concluíram os aprendizes.

As invenções descritas na obra literária despertaram a curiosidade dos estudantes e, por conseguinte, foi possível canalizar o interesse deles para trabalhar a criatividade a fim de resolver um problema proposto. Como objetivo final dessa seção, propusemos às crianças que eles assumissem o papel de cientistas inventores e criassem um objeto cuja finalidade era proteger, salvar os seres fantásticos do pátio de um caçador. Ainda sobre o tema das invenções, cantamos a canção infantil Inventos y Experimentos, de Juana la Iguana ${ }^{4}$, sobre inventos e experimentos; em equipes, fizemos uma caça ao tesouro para colocar em sequência o processo

\footnotetext{
${ }^{4}$ Juana la Iguana é um personagem fictício, originário da Espanha, que estreou em 1996 como uma série infantil de televisão
} 
de criação de um invento. Por fim, diversas armadilhas, obstáculos, máquinas, armas e robôs foram criados para afastar o intruso do pátio.

Figura 7 - Invenções

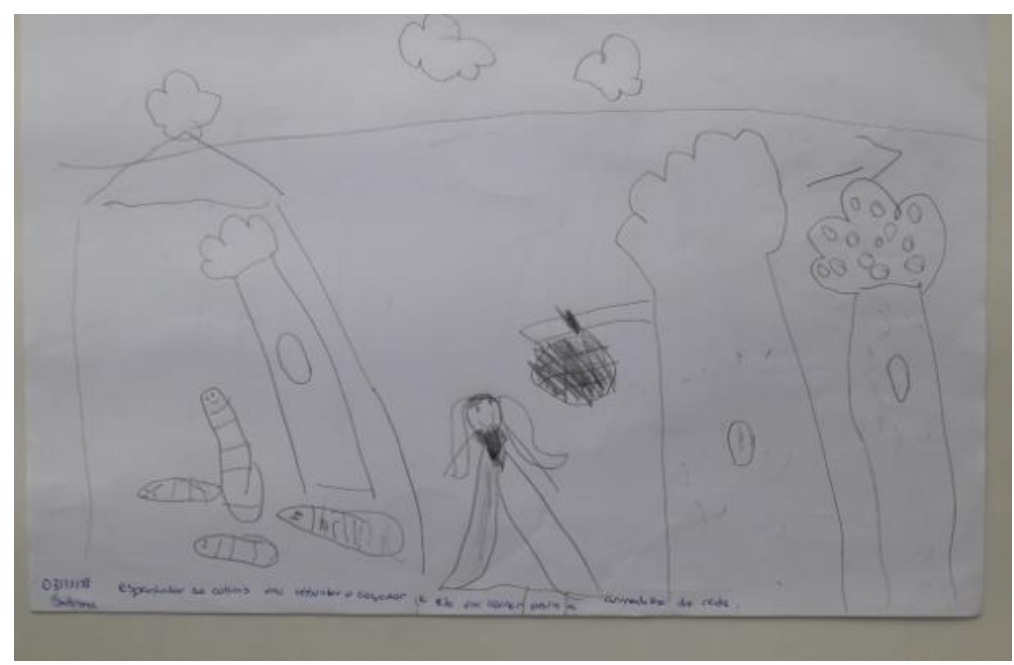

Fonte: Acervo das autoras

Este é o "espantador de cobras", criado por uma aluna do grupo 4. O invento consiste em uma armadilha para prender o caçador composta por duas fases. A primeira é feita com cobras e a segunda, com uma rede. Ao se deparar com as cobras, o invasor se assustaria, correria e cairia na rede.

O último eixo de nosso projeto sobre o Pájaro Amarillo para esse semestre de 2018 foi sobre viagem. Durante as aulas preparadas a partir desse tema, as crianças contaram suas histórias pessoais compartilhando com os companheiros uma viagem realizada em família, desenharam a sua viagem preferida e criaram um habitante para a terra fantástica na qual o personagem principal de Pájaro Amarillo escolheu morar. Esse novo habitante foi construído com rolinho de papel, canetinha, cola e papel crepom. Foram construídos também seres com vários olhos, braços e diferentes cores. 


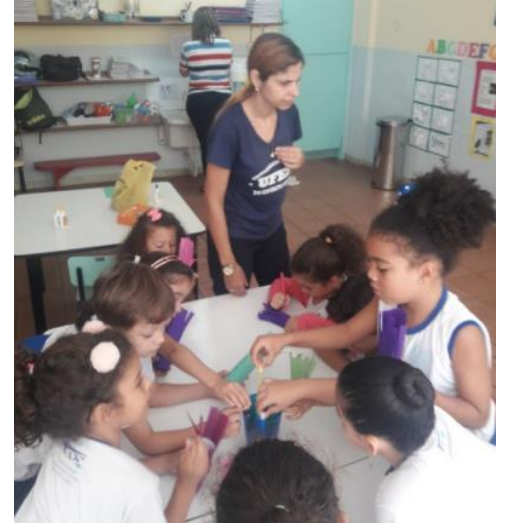

Fonte: Acervo das autoras

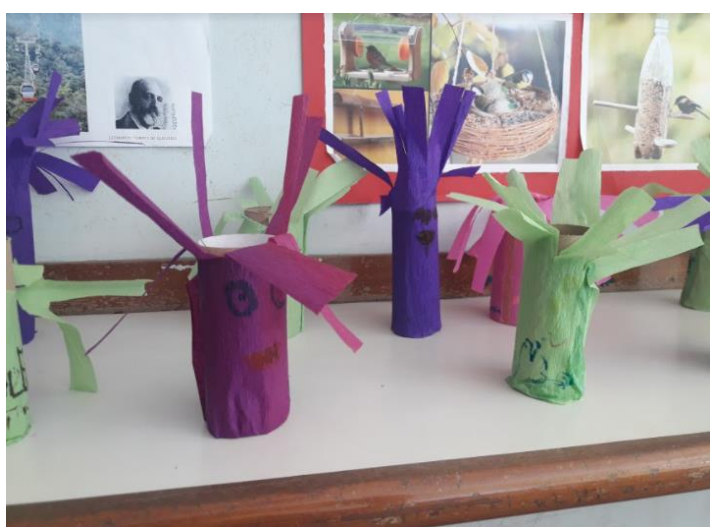

Fonte: Acervo das autoras

\section{A criatividade e a imaginação}

Borges e Mozzer (2008), em seu artigo sobre a criatividade infantil, amparam-se em alguns estudos psicológicos, dos quais puderam concluir que a criatividade envolve o surgimento de algo novo (um produto, um constructo, uma ideia) originado ou não de outro já existente.

Para as autoras, a criatividade é um

processo psíquico que se constrói na criança desde muito cedo e que se desenvolve em conjunto com outras funções superiores como a imaginação, o pensamento, a memória e a brincadeira. A possibilidade de criar está ligada ao contexto histórico, familiar, escolar e à riqueza de experiências vivenciadas pela criança. E, como atividade humana é semioticamente mediada pela cultura. (Borges e Mozzer, 2008, p.1)

A criatividade, então, é uma capacidade cognitiva que está associada ao meio em que a criança está inserida. Se ela se desenvolve em um contexto histórico-social que possibilita e motiva o ato criativo e a capacidade de imaginação, o pensamento criativo será expandido.

A associação da criatividade com o brincar foi outro ponto destacado pelas autoras. Ao brincar, a criança é estimulada a fantasiar, a imaginar e a criar. Analisando os estudos de Vygotsky, elas concluíram que o processo de criação:

não se restringe às grandes invenções da humanidade ou às obras de arte, mas referese à capacidade do homem de imaginar, descobrir, combinar e ultrapassar a experiência imediata. Para ele, quanto mais ricas forem as experiências que as crianças vivenciam, mais possibilidades têm de desenvolver a imaginação e a criatividade em suas ações, especialmente através de suas brincadeiras. E, quanto mais possibilidades tiverem de desenvolver sua imaginação, mais criativas serão nas suas ações/interações com a realidade. (Borges e Mozzer, 2008, p.11) 
O lúdico, portanto, contribui para o desenvolvimento das capacidades cognitivas, pois, em sua execução, a criança coloca em prática diversos processos mentais. No faz de conta, na situação imaginária, a criança realiza uma atividade simbólica na qual ela assume diferentes papéis: cria situações, soluciona problemas, vivencia sentimentos, amplia suas habilidades linguísticas. Desta forma, expande o conhecimento de mundo. Logo, o jogo imaginativo cria um elo entre a fantasia e a realidade.

Por conseguinte, contação de história

\begin{abstract}
deve ser encarada, como uma atividade lúdica e um recurso importante para promover o desenvolvimento das crianças, pois nessa ação estão envolvidos o pensamento, a imaginação, a fantasia e a criatividade. Esta atividade é considerada, também, como uma fonte de prazer e de estímulo à expressão da criatividade. Ao contar, recontar e criar sua própria história, a criança, mesmo ainda não alfabetizada, constrói sentidos e significados, expressa sentimentos, cria seu próprio mundo vivenciando suas fantasias, oportunizando o conhecimento de si e do ambiente que a cerca. (Mozzer, 2008, apud Borges e Mozzer, 2008, p.11-12).
\end{abstract}

\title{
Conclusão
}

Buscamos, neste trabalho, propiciar uma reflexão sobre o processo ensino-aprendizagem de LEC a partir da junção entre as literaturas estrangeiras, nas aulas de línguas, o ensino de LEC e a criatividade, na educação infantil, de maneira lúdica, colaborando, portanto, para um aprendizado contextualizado e significativo da língua espanhola; proporcionando a familiarização com a cultura do outro e da sua própria, bem como o desenvolvimento da criatividade e da imaginação como resultados observados. Entendemos que as literaturas são fundamentais para a aprendizagem de línguas, uma vez que refletem os modos de vida dos povos que as produzem, oferecem repertório para a compreensão do mundo que nos rodeia e também contribuem para a formação emotiva e cidadã do indivíduo.

A literatura em língua estrangeira pode ser apresentada, apreciada e utilizada no ambiente escolar infantil, não só para proporcionar o contato com outro idioma, como também para incentivar o gosto pela leitura, desenvolver a linguagem, a interação social, o pensamento criativo, a imaginação e, também, contribuir para o processo de aprendizagem e desenvolvimento global da criança, pois a leitura literária possibilita ao aluno a ampliação da visão de mundo, desenvolve o sentido de análise e de criticidade; além de provocar prazer, enquanto enriquece o domínio das línguas.

O Pibid Espanhol contribuiu, de forma substancial, para a realização das aulas de espanhol, pois tanto professores do ensino superior, quanto graduandos de Letras Espanhol e professores da rede pública puderam dedicar-se com afinco por algumas horas de seu 
expediente para a realização do projeto, dos planejamentos, dos encontros semanais, a fim de que a construção de uma ideia se tornasse uma realidade. Assim, ampliamos o debate sobre as demandas e as dificuldades atuais do discente e, por conseguinte, sobre as ações e recursos mais eficazes para superação dessas dificuldades. Nesse sentido, permitiu não só a atuação de alunos universitários na sala de aula do ensino básico, como também a aproximação deles a toda a dinâmica de uma escola básica o que, via de regra, ocorre com certa dificuldade nos estágios obrigatórios por causa do curto período de duração.

O tema aqui tratado não se esgota com este trabalho, porém esperamos que este artigo possa contribuir de alguma forma para aqueles que querem atuar como professores de língua estrangeira na educação infantil com práticas atraentes, criativas e significativas para as crianças.

\section{Referências}

ALBERT, R. S.; RUNCO, M. A. A History of Research on Creativity. In Sternberg, R. J. (ed.). Handbook of Creativity. Cambridge University Press.1999.

ALMEIDA FILHO, J.C.P. Dimensões comunicativas no ensino de línguas. São Paulo: Pontes, 1993.

BOÉSSIO. C, P, D. Saberes necessários para o ensino de Língua Espanhola para crianças; revisitando autores. Revista E-curriculum. Pontifícia Universidade Católica de São Paulo. 2010. Disponível in: https://www.redalyc.org/html/766/76619157002/index.html Acesso em 22.05.2019.

BORGES, F. T. e MOZZER, G. N. de S. A CRIATIVIDADE INFANTIL NA PERSPECTIVA DE LEV VIGOTSKI*. Revista Inter Ação, v. 33, n. 2, p. 297-316, 19 dez. 2008. Disponível em: https://www.revistas.ufg.br/interacao/article/view/5269/4314 Acesso em 10 de julho de 2016.

CAMERON, L. Teaching English to Young Learners. Cambridge: Cambridge Univ. Press, 2001.

CANDIDO, A. O direito à literatura. In: CANDIDO, Antônio. Vários escritos. $5^{\mathrm{a}} \mathrm{ed}$. Rio de Janeiro: Ouro sobre Azul, 2011, p. 171-193.

CLÍMACO, A. O; ORTEGA, R. da S.; MILREU, I. (Orgs.). Ensino de Literaturas Hispânicas: Reflexões, propostas e relatos. Campina Grande, PB: EDUFCG, 
2018. http://docs.wixstatic.com/ugd/ff2fac_78d7f9c26ac04f7fb0ed1d517dc3e9f6 Acesso em 15.03.2020

COLOMER, T. "La literatura es el mejor instrumento para adquirir muchas competencias".2017. [Entrevista concedida a Tiching blog] http://blog.tiching.com/teresacolomer-la-literatura-mejor-instrumento-adquirir-muchas-competencias/ Acesso em 05.09.2020

CORRÊA, H. T. Adolescentes leitores: eles ainda existem. In: PAIVA, A. et al (Org.). Literatura e Letramento: espaços, suportes e interfaces - o jogo do livro. Belo Horizonte: Autêntica, CEALE/FaE/UFMG, 2003.

CUNHA, S. R. V. da. As artes no universo infantil. Porto Alegre: Mediação, 2000.

DAVENPORT, T.; PRUSAK, L.; WILSON, H. Quem está lhe trazendo as novas idéias (e como você está respondendo)?. In : HBR Idéias de Impacto. p. 42-48, fev., 2003.

DIOS, O. Pájaro Amarillo. Zaragoza: Apila, 2015.

ESCALANTE, D.T. \& CALDERA, R. V. (2008). Literatura para niños: Una forma natural de aprender a leer. Revista EDUCERE: Artículos arbitrados, nº 43, pp. 669-678.

LIGHTBOWN, P. \& SPADA, N. How Languages are Learned. 3 rd Ed. Oxford, 2006.

MOON, J. Children learning English. Oxford: Macmillan, 2005.

PATY, M. A criação científica segundo Poincaré e Einstein. Estudos Avançados, v. 15, n. 41, p. 157-192, abr. 2001. Disponível em http://www.scielo.br/scielo.php?script=sci_arttext\&pid=S0103-

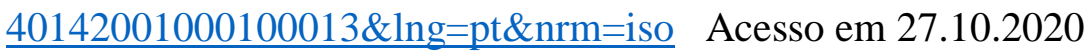
PEREIRA, J, C, M, Q. O ensino de língua inglesa na Educação Infantil; considerações sobre teoria e prática. 2016. 169 f. Dissertação de Mestrado - Pontifícia Universidade Católica de São $\quad$ Paulo $\quad-\quad$ USP. http://tede2.pucgoias.edu.br:8080/bitstream/tede/1183/1/CRISTINA\%20PEREIRA\%20FURT ADO.pdf

PIAGET, J. Criatividade. In: VASCONCELOS, M. S. (Org.). Criatividade: psicologia, educação e conhecimento do novo. São Paulo: Moderna, 2001. 


\section{RINALDI, S. Um retrato da formação de professores de Espanhol como língua estrangeira} para crianças: um olhar sobre o passado, uma análise do presente e caminhos para o futuro. 2006. 171 f. Dissertação de Mestrado - Faculdade de Educação da Universiadade de São Paulo - USP. Disponível em:

https://www.teses.usp.br/teses/disponiveis/48/48134/tde-21062007-110155/pt-br.php Acesso em 18.10.2018

ROCHA, C.H. O ensino de línguas para crianças no contexto educacional brasileiro: breves reflexões e possíveis provisões. In: DELTA v. 23, n. 2, p. 273 - 319, 2007.

ROCHA, C. H. A língua inglesa no ensino fundamental público: diálogos com Bakhtin por uma formação plurilíngue. In: Trabalhos em Linguística Aplicada, Campinas, 48(2): 247-274, Jul./Dez. 2009.

SILVA, M. F. M. Definição e avaliação da criatividade: contributos da abordagem cognitiva. Tese de Doutorado não publicada. Instituto de Educação e Psicologia, da Universidade do Minho. Minho: Portugal, 1999.

SCHUTZ, R. A evolução do aprendizado de línguas ao longo de um século. English made in Brazil. 2007. Disponível no endereço eletrônico: http://www.sk.com.br/sk-apren.html. Acesso em 16.02.2010.

TOMMASI, S. M. B. Criatividade e educação (Parte 2). Revista Direcional, jun. 2010, p. 3435 .

TONELLI, J. R. A. Histórias infantis no ensino da língua inglesa para crianças. Dissertação de mestrado. Mestrado em Estudos da Linguagem. Universidade Estadual de Londrina. 2005. Disponível em:

http://www.leffa.pro.br/tela4/Textos/Textos/diserta_online/Juliana_Tonelli Acesso em $\underline{05.02 .2021}$

VIGOTSKI, L.S. Imaginação e criação na infância: ensaio psicológico- livro para professores; apresentação e comentários Ana Luiza Smolka; tradução Zoia Prestes. São Paulo: Ática, 2009. 